\title{
Pelizaeus-Merzbacher disease: a form of sudanophil leucodystrophy
}

\author{
R. M. NORMAN, A. H. TINGEY, P. W. HARVEY, AND A. M. GREGORY \\ From the Burden Neuropathological Laboratory, Frenchay Hospital, Bristol, the Royal Lancaster \\ Infirmary, and the Royal Albert Hospital, Lancaster
}

'Pelizaeus-Merzbacher disease' appears in all classifications of the demyelinating diseases and the impression is given the the name connotes a distinct nosological entity. Certainly the detailed clinical and pathological descriptions of the original cases could hardly have been improved, but with the passage of time a clear definition of the disease has become obscured by the admission into the category of too many cases showing marked variations from the classical condition as described by Merzbacher (1910) and Pelizaeus (1885).

In the original family the disease was inherited as a sex-linked Mendelian recessive. Neurological signs usually appeared by the third month in the form of nystagmoid eye movements and tremor of the head. The children became spastic, ataxic, mentally defective, and physically stunted but after some years the illness showed little or no progression and life was often prolonged well into adult life. One of the affected sibs was examined neuropathologically by Merzbacher (1910) and another by Spielmeyer (1923) and Liebers (1928). Widespread demyelination was found in the centrum ovale, cerebellum, and parts of the brain-stem. Axis cylinders were preserved and throughout the white matter there was a diffuse fibrous gliosis. Small amounts of sudanophil lipid were present as perinuclear droplets or in fat granule cells around vessels. A peculiar feature was the presence of conspicuous 'myelin islands' in the demyelinated areas. These patches of preserved fibres were often perivascular and gave a spotty, 'tigerskin' (better 'leopard-skin') appearance to sections stained for myelin. This striking discontinuity of the demyelination seemed to differentiate the condition morphologically from other forms of diffuse cerebral sclerosis, and the presence of myelin islands has been adopted by most subsequent authors as an essential criterion for pathological diagnosis.

By the time Seitelberger (1954) came to write his comprehensive review of the subject it was clear that the name 'Pelizaeus-Merzbacher disease' had been given to a heterogeneous collection of conditions varying considerably in the age of onset, rapidity of course, genetic background, and even pathological features. Thus in Wicke's (1938) case and in that of Jacobi (1947, case 2) myelin islands were only poorly visible against a background of generally reduced intensity of myelin staining, there being no complete loss of fibres. On the other hand, in the three siblings described by Seitelberger (1954), there was an almost complete absence of myelin throughout the brain and spinal cord, though a few patches of preserved fibres were found in the brain of the youngest child. A further variant was the 'adult type' of Löwenberg and Hill (1933) in which a closely-set, flaky form of demyelination gave a mottled appearance. This condition was later shown to be inherited as a dominant by Camp and Löwenberg (1941).

In an attempt to improve this unsatisfactory state of classification, Norman and Tingey $(1961,1963)$ suggested that since the great majority of these cases showed evidence of myelin breakdown in the form of sudanophil, doubly refractile products, these evidently diverse conditions, should be broadly grouped together as varieties of sudanophil leucodystrophy. The type with virtually no myelin could well be called 'sudanophil leucodystrophy of the Seitelberger type' while the form more closely resembling the original cases should be called 'sudanophil leucodystrophy of Pelizaeus-Merzbacher type'. This change in nomenclature has been supported with slight modifications by Peiffer (1962), Bargeton, Lyon, Ribierre, and Joseph (1962) and Diezel, Fritsch, and Jakob (1965). The last authors now divide cases previously called Pelizaeus-Merzbacher disease into two main groups of sudanophil (orthochromatic) leucodystrophy, namely, the congenital type (Seitelberger) with virtually no myelin, now comprising eight cases, and a larger, more heterogeneous group II, of 20 cases, with flaky ('fleckförmiger'), discontinuous demyelination. The latter includes four cases of the classical Pelizaeus-Merzbacher type with sharply contoured myelin islands, to which the new example reported by Garcin, 
Lapresle, and Berger (1965) may be added. It has recently been proposed that this second group should be enlarged by the inclusion of 10 cases comprising the syndrome of micrencephaly, dwarfism, and symmetrical cerebral calcifications, since discontinuous demyelination with myelin islands is a constant feature of this condition (Norman and Tingey, 1966). The recent case of Gerstl, Malamud, Hayman, and Bond (1965) probably belongs to this subgroup.

A more drastic solution to the problem of classification has been proposed by Zeman, Demyer, and Falls (1964), who believe that the diagnosis of Pelizaeus-Merzbacher disease can only be made correctly on clinical and genetic grounds. Their rejection of pathological criteria may have been influenced by the fact that the brains and spinal cords of their three patients all showed the same diffuse absence of myelin as in the Seitelberger type, that is to say, the very changes which others have wished to exclude from the category. If sex-linked inheritance has to be proved before the diagnosis of PelizaeusMerzbacher disease can be made, the condition becomes one of the rarest of neurological disorders, and another name has to be found to describe sporadic cases with neuropathological features similar to those of the classical cases (as that of Garcin et al.), and also for those with the same pathological features as reported by Zeman et al. but with a different genetic background (as Seitelberger's cases).

One sees here a conflict between discordant clinical and pathological criteria for the definition of a disease. Since neuropathology has hitherto played an essential part in the delineation of the various forms of leucodystrophy, we believe that it would be premature to abandon this line of investigation. Some of these problems will be taken up again in the light of the case now to be described.

CASE REPORT

FAMILY HISTORY The patient R.S. was the third child of healthy parents. Both the other sibs had died in infancy, one at birth, the other aged 3 days with congenital heart disease. From the detailed information obtained from the mother it was established that the grandparents, uncles, aunts, and their children did not show evidence of neurological disease except for some instances of cardiovascular disorders in late life.

PREGNANCY AND DELIVERY The mother stated that her pregnancy was normal and uneventful except that the gestation period was two weeks longer than usual. No foetal abnormalities were disclosed by abdominal radiographs but the position of the baby had to be altered. The patient was born in a maternity Hospital by Caesarian section after a brief trial of labour. The birth weight was $5 \mathrm{lb} .10 \mathrm{oz}$.
POST-NATAL The patient was a slow feeder with a poor suck and was slow to put on weight. He sat up at 6 months and pulled himself up into a standing position at 18 months, but by the age of 2 years he had not progressed and was seen by a paediatrician. He was found to have a spastic quadriplegia, most marked in the lower limbs, and a diagnosis of cerebral palsy was made. Subsequently, he was never able to walk or crawl and was eventually confined to a wheel-chair. He failed to develop control over his bladder or rectum and remained doubly incontinent throughout life. In addition, he was unable to feed himself owing to a tremor in both hands. In his fourth year he was admitted to an orthopaedic hospital for a six-month stay with a view to education in walking, but on discharge his mother claimed that there were signs of deterioration, because he was now unable to pull himself into a standing position. At the age of 5 years, he was examined by an educational psychologist who reported that a mental age of just over 3 years represented the probable upper limit of his intellectual capacity. At the age of 6 years, he was examined by a cerebral palsy unit and, in addition to spasticity, was found to have a gross ataxia with persistent coarse horizontal nystagmus. He was then admitted to a special school, where he remained for five years. From the date of his return home his condition began to deteriorate markedly. He developed episodic outbursts of temper, ataxia became pro $\mathrm{N}$ gressively worse, and he was admitted to hospital to give his mother a rest from the continuous strain of caring for him. On admission he was $3 \mathrm{ft}$. 9 in. tall and weighed $\rightarrow$ 2 st. $10 \mathrm{lb}$. He was found to have spasticity of all fout5 limbs which was most marked in the legs. He could nơ stand without support and, when assisted, his gait wos grossly ataxic. Active movements provoked a sever tremor of both hands and arms. Continuous horizont nystagmus appeared on looking to the right and left $\vec{\theta}$ A detailed neurological examination was impracticable owing to the patient's inability to cooperate. Before further investigations could be carried out, he developed acute bronchopneumonia which proved resistant to antibiotics, and died within a week of admission to hospital, aged 11 years 9 months.

\section{NECROPSY FINDINGS}

The body was that of a young male child whose appearance did not suggest that he was as mature as a boy of 12 years. Except for bilateral bronchopneumonia, abnormality was confined to the nervous system. The brain on section showed a greyish discoloration and shrinkage of the centrum ovale which suggested degeneration and no further dissection was made before fixation.

\section{NEUROPATHOLOGICAL EXAMINATION}

MACROSCOPIC The brain weighed $833 \mathrm{~g}$., the cerebellum and brain-stem accounting for $96 \mathrm{~g}$. The $\tilde{\sigma}$ frontal and parietal lobes were irregularly convoluted. The gyri were few and unduly massive and on section 
showed multiple folds in the cortical ribbon which were not separated by sulci. The lateral ventricles were moderately enlarged. The corpus callosum, centrum ovale, and gyral cores were greyish in colour, suggesting demyelination. Here and there patches of more normal looking white matter were seen, mainly in parts of the internal capsules, subcortical fibres, and periphery of gyral cores. The cerebellum showed marked shrinkage of the folia and a reduction in the volume of the central white matter which appeared sclerosed and patchily demyelinated. The brain-stem was small and tough, with little distinction between grey and white matter.

MICROSCOPIC Representative regions of the cerebral hemispheres, basal ganglia, cerebellum, and brainstem were examined in frozen and celloidin sections stained for nerve cells, axis cylinders, myelin, fibrous neuroglia, and lipid.

Changes in the white matter In celloidin sections myelin sheaths, where present, stained very feebly throughout almost the whole brain, and the following description is based mainly on frozen sections which revealed considerably more fibres because of a much greater intensity of their staining. Myelin sheaths were almost absent in the cerebral cortex and grossly deficient throughout the gyral cores and centrum ovale, especially in the anterior part of the frontal lobes. At the level of the mammillary bodies (Fig. 1), there were myelinated bundles in the internal capsules and a few less dense patches in some of the gyral cores. The majority of the fibres in these patches stained very feebly even in frozen sections, and appeared as thin grey tubes. In the macroscopically visible patches there were numerous dark fibres, usually showing irregular staining and sometimes beading, and these were often interspersed with pale, thin fibres of the type just described. The anterior commissure was completely devoid of myelin and in the optic tract only the ventral fibres were well stained. At mid-thalamic level (Fig. 2a) the internal capsule contained substantial numbers of myelinated fibres, while in the temporal lobe only the optic radiation was visible. The occipital lobes showed a few clear-cut myelin islands, some of which were in the cortex, and also a flaky, discontinuous loss in the optic radiations and in other scanty fibre bundles (Fig. 4).

Each globus pallidus showed a diffuse rarefaction of myelinated fibres. The fibre bundles in the putamina were represented by sparse strands. The lateral nucleus of the thalamus, the subthalamic region, pretectal area, and external geniculate bodies contained abundant well-stained fibres but their numbers were many fewer than the normal (Fig. 2a). The anterior and medial nuclei of the thalamus were virtually demyelinated except for part of the anterior thalamic peduncle.

In the cerebellum the denser myelination of the hilum and much of the fleece of the dentate nucleus contrasted with the flaky demyelination of the remainder of the central white matter. The cores of the gyri showed a curious central demyelination (Fig. 5) and the fibres of the granular layer were rarefied and beaded.

Considerable variation in myelination was seen in different levels of the brain stem. The tegmentum of the midbrain showed no complete demyelination but there was a diffuse thinning of fibre density. Even the better myelinated central parts, including the median longitudinal fasciculus and brachium conjunctivum, were much less dense and showed more variation in the staining of individual fibres than in control sections. There was severe demyelination of the crura. The oculomotor nerves were fully myelinated (Fig. 6). The tegmentum of the upper pons showed the same general reduction in fibre density, while the central parts of the pes pontis were demyelinated. At the level of the superior olive the transverse fibres and middle cerebellar peduncle were almost completely demyelinated while the cortico-spinal tracts contained a substantial number of fibres. The mesial fillet was less affected and symmetrical patches of fibres were preserved in the tegmentum. The cranial nerves stained normally, both in their intra- and extra-cerebral parts (Fig. 7). In the medulla the pyramids, parts of the restiform bodies, and the median raphé were relatively well myelinated, but elsewhere there were small islands (as in the inferior olives) or vaguer patches of fibres set against a background of diffuse myelin poverty (Fig. 8).

The spinal cord was not available for examination.

Axis cylinders were fully preserved in all demyelinated parts of the white matter (Fig. 9) although in the centrum ovale they were generally of a very narrow calibre and not deeply impregnated by the Gros-Bielschowsky method. Fibrous gliosis of isomorphic type was a marked feature of the whole of the white matter and there was little relationship between intensity of gliosis and demyelination (Fig. 2b). Oligodendroglial nuclei were absent or greatly reduced in numbers even in the better myelinated areas.

Bright red sudanophil lipid was present in small amounts in many parts of the white matter, especially in the internal capsules and crura. These lipid deposits were doubly refractile, readily soluble in alcohol, mainly Marchi positive, and were extracellular. They occurred chiefly in the perivascular spaces (Fig. 10), some of which were greatly enlarged. 


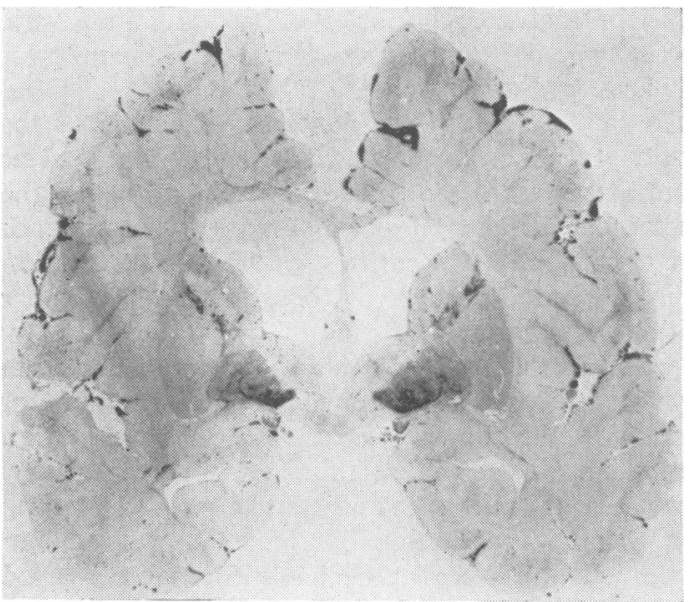

FIG. 1. Coronal section of the brain showing widespread absence of myelin. Heidenhain's stain for myelin (celloidin).

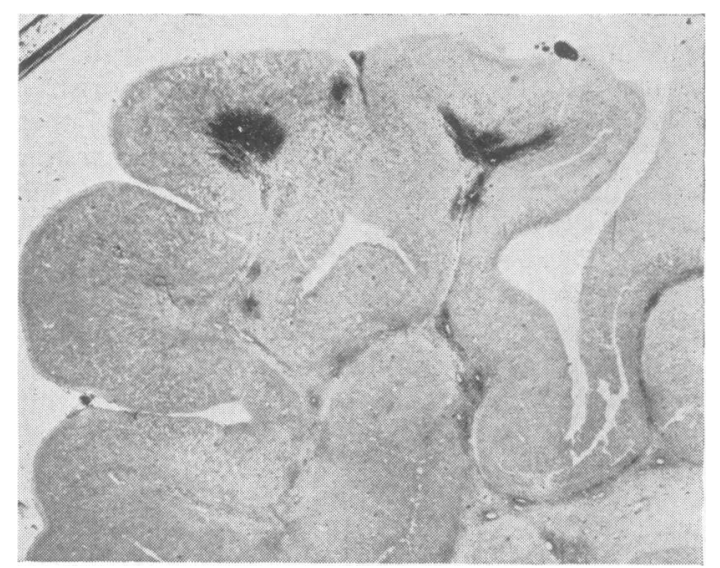

FIG. 3. Occipital pole. Myelin islands. Kultschitsky-Pal (frozen) $\times 4$.

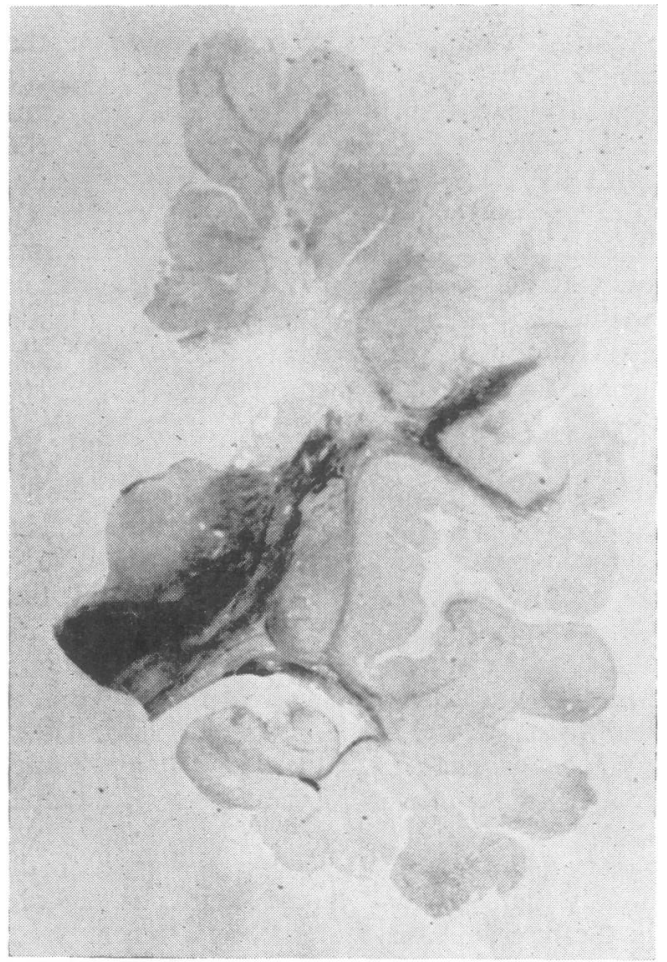

FIG. 2a.

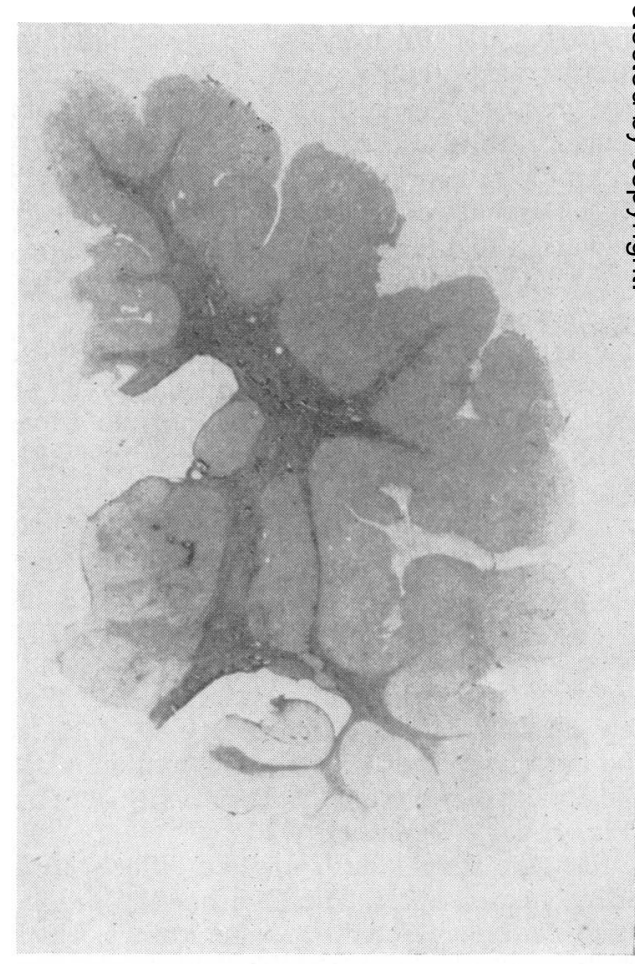

FIG. $2 b$.

FIG. 2a. Right hemisphere showing the distribution of myelinated fibres. Kultschitsky-Pal (frozen) $\times 1$.

FIG. 2b. Diffuse fibrous gliosis in the cerebral white matter. Holzer (frozen) $\times 1$. 


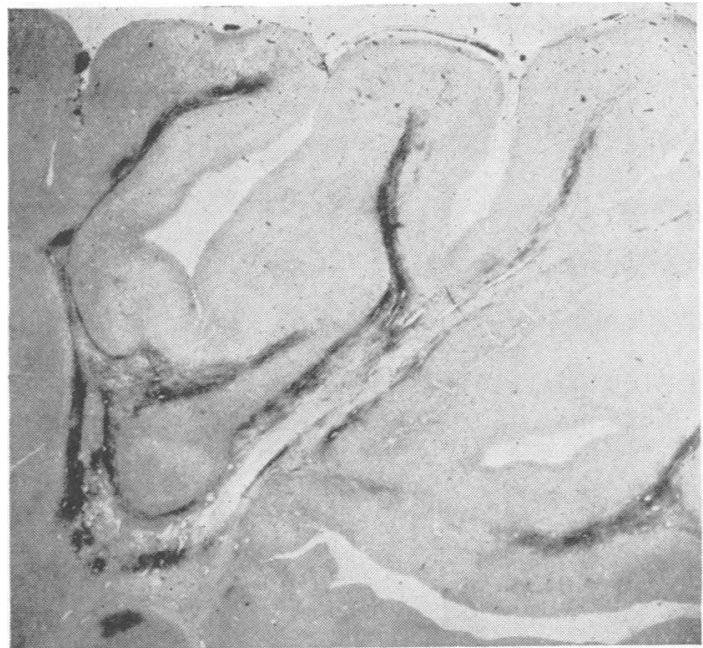

FIG. 4. Occipital lobe. Discontinuous type of demyelination. Kultschitsky-Pal (frozen) $\times 3 \cdot 2$.



FIG. 6. Midbrain. Diffuse demyelination of the tegmentum with better preserved brachia conjunctiva, mesial fillet, and brachium colliculi inferioris. The oculomotor nerve fibres stain well. Kultschitsky-Pal (frozen) $\times 6 \cdot 8$.

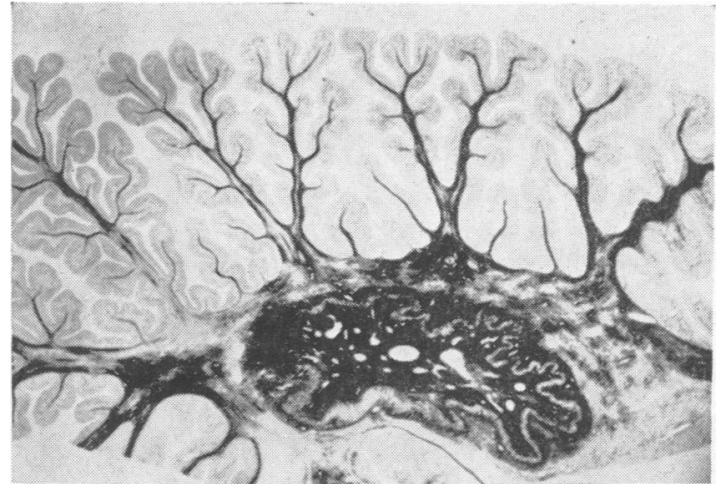

FIG. 5. Cerebellum. Flaky demyelination in the white matter. Central demyelination in the gyral cores. Kultschitsky-Pal (frozen) $\times 2 \cdot 7$.

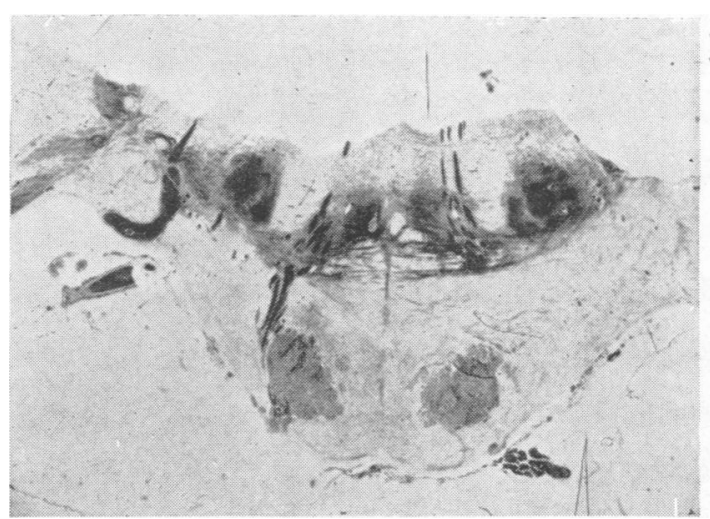

FIG. 7. Lower pons. Patchy demyelination of tegmentum. Pes pontis demyelinated except for cortico-spinal tracts. Heidenhain (celloidin) $\times 4 \cdot 5$.

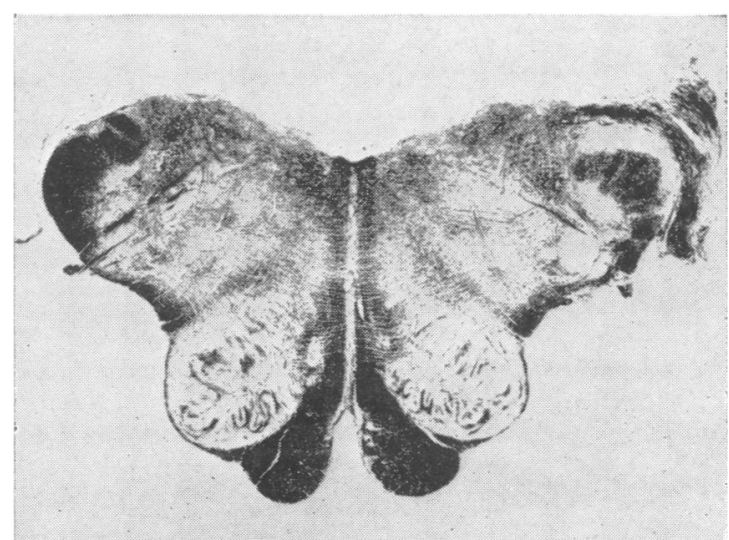

FIG. 8. Medulla. Diffuse demyelination. Relative preservation of restiform bodies and pyramids. The inferior olives contain numerous small myelin islands. KultschitskyPal (frozen) $\times 3$. 


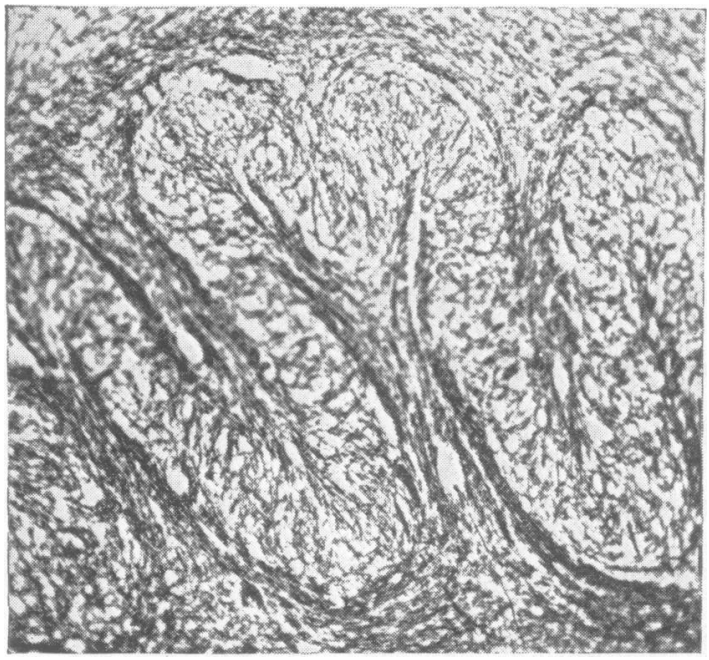

FIG. 9. Demyelinated part of inferior olive. The axis cylinders are normal. Gros-Bielschowsky (frozen) $\times 68$.

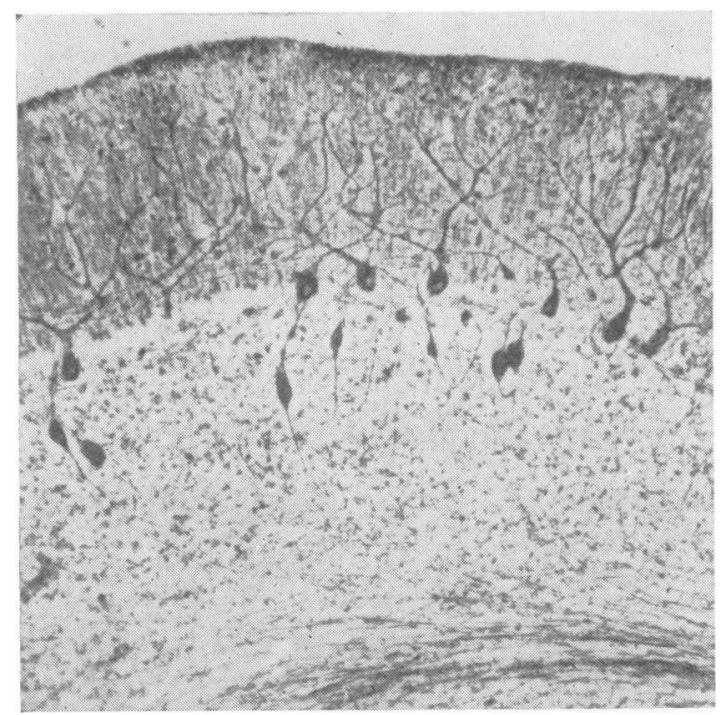

FIG. 11. Cerebellum. Rarefaction of the granular layer and preservation of Purkinje cells, the axons of which show 'torpedoes'. Cajal's silver nitrate-pyridine method $\times 126$.

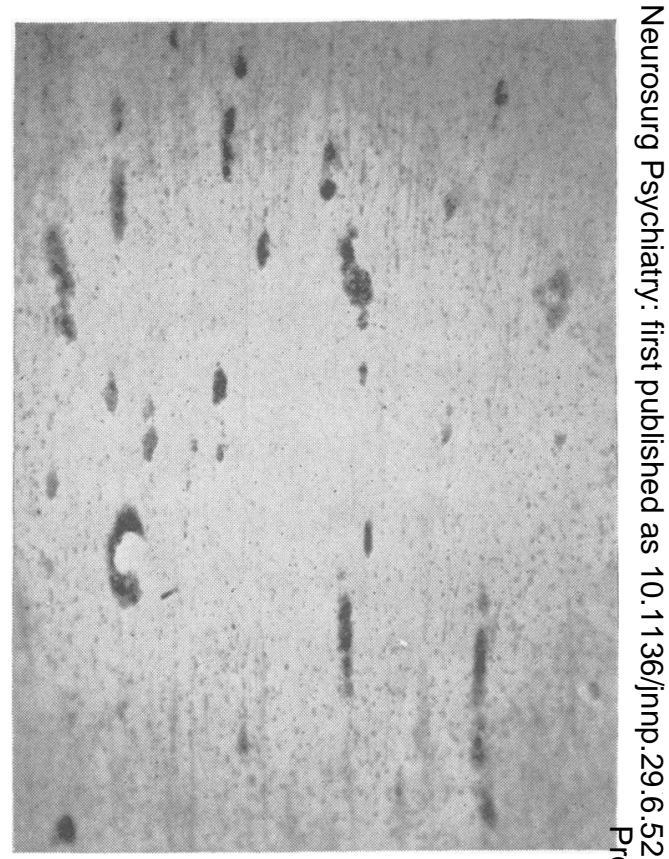

FIG. 10 Perivascular sudanophil lipid in centrum ovale

Scharlach R. × 60 .

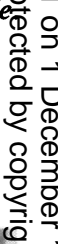

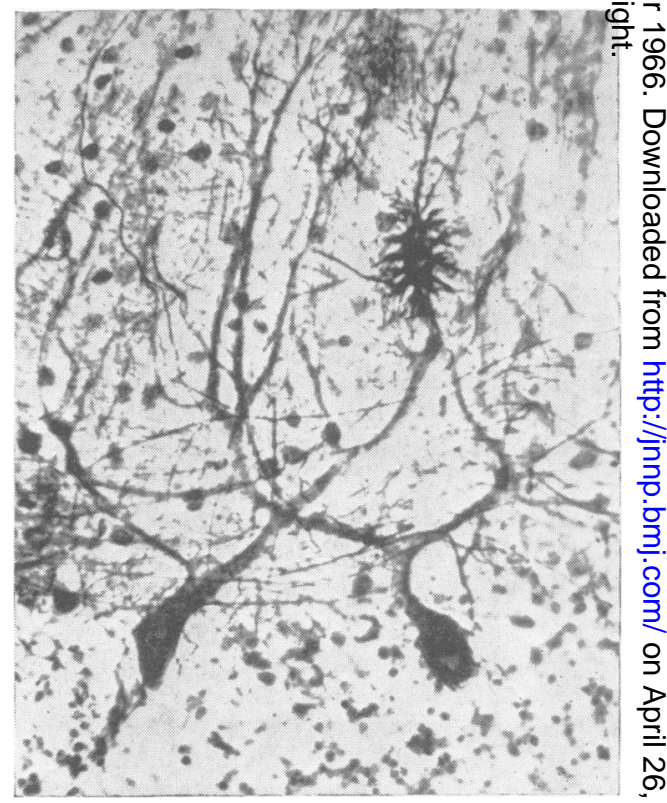

FIG. 12. Purkinje cell with dendritic expansion. Cajal's silver nitrate-pyridine method $\times 280$. 




FIG. 13. Microgyric malformation of the cerebral cortex. Carbol azure $\times 5$.

No fat granule cells were seen in the tissues.

Changes in the grey matter The cerebellar cortical atrophy was distinguished by a rarefaction of the granular layer (Fig. 11) which was diffusely present except in the well-preserved biventral lobe and tonsil. Only minor losses had occurred in the layer of Purkinje cells. The latter showed occasional axonal 'torpedoes' and cactus-like dendritic expansions (Figs. 11 and 12). The tangential and basket fibres were well represented. A single oval heterotopic collection of mixed Purkinje and granule cells was seen in the white matter. The dentate nuclei were unremarkable. The malformed parts of the cerebral cortex showed prenatal microgyria. Multiple small folds of the cortical grey matter were separated from each other by acellular bands representing undivided molecular layers. These formations sprouted from larger convolutions in the central cores of which there were abundant heterotopic nerve cells arranged in long strands or small islands (Fig. 13).

Small areas of neuronal loss were found in the thalami. The globus pallidus contained an excess of pigment but no calcifications. Elsewhere in the brain (except for the abnormalities already described), the grey matter was unremarkable.

There were no pathological changes in the meninges, choroid plexus, ependyma, or cerebral vessels.

\section{CHEMISTRY}

The analytical methods were those used in previous work (Tingey and Edgar, 1963) and the results are shown in the Table. The extent of the demyelination found in the white matter was reflected in the very low values of total lipid, free cholesterol, total phospholipid and particularly in the extremely low neutral hexose (from which true cerebroside is calculated). The chemical estimation of sphingomyelin was unsatisfactory because of formalin fixation, but thin-layer chromatography showed a substantial reduction. The water content was as large as in the neonatal brain. The unequivocally high levels of lipid hexosamine, neuraminic acid, and residual hexosamine are features common to leucodystrophies of different types, the former being particularly indicative of an endogenous disease of myelin (Edgar, 1961; Bargeton-Farkas and Edgar, 1964). Lipid hexosamine was also greatly increased in the cerebral cortex which was otherwise not obviously abnormal except for the low neutral hexose.

TABLE I

\begin{tabular}{|c|c|c|c|c|}
\hline \multicolumn{5}{|c|}{ VALUES OF CHEMICAL BRAIN CONSTITUENTS ${ }^{1}$} \\
\hline & \multicolumn{2}{|c|}{$\begin{array}{l}\text { Cerebral White } \\
\text { Matter }\end{array}$} & \multicolumn{2}{|c|}{ Cerebral Cortex } \\
\hline & Normal & Case R.S. & Normal & Case R.S. \\
\hline Total lipid & $62 \cdot 0$ & $27 \cdot 4$ & $37 \cdot 0$ & 30.0 \\
\hline Cholesterol free & $14 \cdot 0$ & $4 \cdot 5$ & $5 \cdot 8$ & $6 \cdot 2$ \\
\hline Cholesterol ester & 0.2 & 0.4 & Nil & Nil \\
\hline Total phospholipid & $22 \cdot 9$ & $12 \cdot 7$ & $19 \cdot 8$ & 16.6 \\
\hline Lecithin & $6 \cdot 3$ & $7 \cdot 8$ & 6.0 & 9.0 \\
\hline Total lipid hexose & $3 \cdot 72$ & 0.25 & 1.06 & 0.60 \\
\hline Neutral hexose & $2 \cdot 00$ & 0.09 & 0.40 & $0 \cdot 12$ \\
\hline Lipid hexosamine & 0.045 & $0 \cdot 147$ & $0 \cdot 146$ & 0.223 \\
\hline Neuraminic acid & 0.058 & $0 \cdot 230$ & 0.409 & 0.229 \\
\hline Residue hexosamine & 0.195 & 0.478 & 0.485 & 0.427 \\
\hline Water & $71 \cdot 6$ & 88.9 & $84 \cdot 7$ & $87 \cdot 4$ \\
\hline
\end{tabular}

${ }^{1}$ All values (except water) in g./100 g. of dry tissue.

\section{DISCUSSION}

In this child the diagnosis of cerebral palsy in the sense of a consequence of birth injury was soon disproved by the progressive nature of the neurological illness. The predominant signs of ataxia and nystagmus were in harmony with the severe cerebellar corticalatrophy found neuropathologically. Although there was no evidence of sex-linked inheritance, the diagnosis of Pelizaeus-Merzbacher disease might have been justified in view of the early and probably congenital onset, the mental and physical retardation and the prolonged course of the illness.

Neuropathologically this case had certain features found in both of the groups of sudanophil leucodystrophy defined by Diezel et al. (1965). The extreme poverty of myelinated fibres in much of the centrum ovale and in the cerebral cortex was equivalent to that characterizing the congenital type $I$. Chemically, the white matter showed an extremely 
low level of neutral hexose (cerebroside), even lower than what has been found in other examples of the congenital form (Norman and Tingey, case 2, 1963; Bargeton-Farkas and Edgar, 1964). These values are considerably less than those in the normal neonatal brain or, in our experience, in other forms of leucodystrophy (Tingey and Edgar, 1963). On the other hand, the patchy demyelination in the cerebellum and brain-stem, and the more sharply contoured myelin islands in the occipital lobes, were more characteristic of the second group of this classification, which includes the majority of cases previously designated Pelizaeus-Merzbacher disease. The preservation of axis cylinders, the diffuse isomorphous fibrous gliosis, and the sudanophil lipid deposits are shared by both groups. Since classification must depend on the overall picture, this case clearly belongs to the second group.

Zeman et al. (1964) attributed the absence of myelin in their congenital cases to a defect of myelinogenesis rather than to 'demyelination', despite the heavy gliosis in the 'white matter'. The transitional features of our case suggest that a disturbance of myelin synthesis had been only one factor in a complex disorder involving not only the formation of myelin but its maintenance. An element of demyelination can hardly be denied in view of the sudanophil lipid present in the tissues and the pathological appearances of the majority of the remaining myelinated fibres. In our opinion, these are expressions of a slow degeneration. It is precisely this conception of a degenerative process occurring in abnormally constituted myelin sheaths which Poser (1962) has formulated in his theory of 'dysmyelination' in the leucodystrophies.

Although our case was sporadic, it is evidently a leucodystrophy because of its histological and chemical features. The high level of lipid hexosamine found in the white matter and cortex is highly characteristic of this group of endogenous disorders and is one of several distinguishing points from Schilder's disease (Edgar, 1961).

The atrophy of the granular layer of the cerebellum found in this case is a feature shared by sudanophil and metachromatic leucodystrophy. It has been reported in some of the congenital sudanophil cases (Seitelberger, case 2, 1954; Peiffer and Zerbin-Rüdin, case 2, 1963; Diezel et al., case 2, 1965), and in a diffuse type of sudanophil leucodystrophy without myelin islands (Norman, Tingey, Valentine, and Danby, 1962). No explanation can be offered as to why this layer is so vulnerable unless its atrophy represents an effect shared in common by different genes.

A similar problem is raised by the combination of cerebral cortical malformations with leucodystrophy.
This association cannot be regarded as fortuitous. Microgyria of developmental type, as seen in our case, has been found in the congenital form of sudanophil leucodystrophy by Seitelberger (case 1, 1954), and one of the siblings reported by Diezel et al. (case 2, 1965) showed maldevelopment of cortical lamination, though without gross gyral anomalies. Prenatal microgyria has occurred in an atypical form of leucodystrophy characterized by mixed sudanophil and pre-lipid accumulations (Norman, Urich, and Tingey, 1963). Pachygyria was present in the case of diffuse sudanophil leucodystrophy described by Norman et al. (1962). The pathogenesis of these cortical maldevelopments is not fully understood but it is generally agreed that one factor involved in both micro- and pachygyria is a retardation in neuronal migration. In the conditions under consideration, it would seem that the gene responsible for the disturbances in the metabolism of myelin may have an additional and much more precocious effect upon neuronal organization. The same genetic principle is illustrated by a combination of pathological changes sometimes found in maple syrup urine disease. In this metabolic disease of infants, severe degeneration of myelin sheaths may be associated with prenatal cerebraf malformation. The three brains described by Peiffer and Solcher (1965) showed heterotopic collections of nerve cells in the cerebral white matter, and in the case reported by Martin and Norman (1966) there was extensive prenatal microgyria of the cerebras cortex.

It is instructive to find gathered together in a single brain so many features previously reported in both Pelizaeus-Merzbacher disease and the leucodystrophies. There is no doubt that in the past this case would have been consigned unhesitatingly to the former overloaded category. In our view, the few sharply contoured myelin islands in this brain are not a sufficient reason to classify the case in this way, and the less specific category of 'sudanophil leucodystrophy type 2' is now available. The classification proposed by Diezel $e t$ al. is certainly provisional but it represents the first logical step in the dismemberment of this complex group of disorders.

\section{SUMMARY}

A boy aged 11 years 9 months at death had shown signs of a progressive neurological illness with onset in early life and accompanied by mental and physical retardation. The main features were spasticity, ataxia, and nystaginus. Neuropathological examination showed micropolygyria in parts of the cerebral cortex, severe demyelination in the centrum ovale with some preserved islands of myelinated fibres, a 
patchy discontinuous type of demyelination in the cerebellum and brain-stem, and an atrophy of the granular layer of the cerebellum. The white matter contained a normal number of axis cylinders and there were scanty sudanophil, doubly refractile and Marchi-positive lipid deposits. Chemically, the white matter showed very low levels of cerebroside, cholesterol, and phospholipid, and there was a marked increase in lipid hexosamine and ganglioside.

A review has been given of the variable criteria upon which the diagnosis of Pelizaeus-Merzbacher disease is currently based. While it is conceded that this name could be applied loosely to the condition described in the present patient, reasons are given for preferring to classify the case less specifically as one of sudanophil leucodystrophy, mainly because it does not conform sufficiently closely to the classical form of the disease for which the eponym should be strictly reserved.

\section{REFERENCES}

Bargeton, E., Lyon, G., Ribierre, M., and Joseph, R. (1962). Leucodystrophie sudanophile congénitale: observation anatomoclinique. Arch. franc. Pédiat., 19, 495-509.

Bargeton-Farkas, E., and Edgar, G. W. F. (1964). Anatomo-chemical studies on a case of congenital sudanophilic leucodystrophy. Acta neuropath. (Berl.), 3, 578-387.

Camp, C. D., and Löwenberg, K. (1941). An American family with Pelizaeus-Merzbacher disease. Arch. Neurol. Psychiat. (Chic.), 45, 261-264.

Diezel, P. B., Fritsch, H., and Jakob, H. (1965). Leukodystrophie mit ortho-chromatischen Abbaustoffen: Ein Beitrag zur PelizaeusMerzbacherschen Krankheit. Virchows Arch. path. Anat., 338, 371-394.

Edgar, G. W. F. (1961). Neurochemical aspects of leucodystrophy. Psychiat. Neurol. Neurochir. (Amst.), 64, 28-36.

Garcin, R., Lapresle, J., and Berger, B. (1965). Etude anatomoclinique d'un cas de maladie de Pelizaeus-Merzbacher. Rev. neurol., 112, 449-466.

Gerstl, B., Malamud, N., Hayman, R. B., and Bond, P. R. (1965). Morphological and Neurochemical study of Pelizaeus-Merzbacher disease. J. Neurol. Neurosurg. Psychiat., 28, 540-547.

Jacobi, M. (1947). Uber Leukodystrophie und Pelizäus-Merzbachersche Krankheit. Virchows Arch. path. Anat., 314, 460-480.
Liebers, M. (1928). Zur Histopathologie des Zweiten Falles von Pelizaeus-Merzbacherschen Krankheit. Z. ges. Neurol. Psychiat. (orig.), 115, 487-509.

Löwenberg, K., and Hill, T. S. (1933). Diffuse sclerosis with preserved myelin islands. Arch. Neurol. Psychiat. (Chic.), 29, 1232-1245.

Martin, J. K., and Norman, R. M. (1966). Maple syrup urine disease in an infant with microgyria. Develop. Med. Child Neurol., in the press.

Merzbacher, L. (1910). Eine eigenartige familiär-hereditäre Erkrankungsform (Aplasia axialis extracorticalis congenita). Z. ges. Neurol. Psychiat. (orig.), 3, 1-138.

Norman, R. M., and Tingey, A. H. (1963). Sudanophil leucodystrophy and Pelizaeus-Merzbacher disease. In Brain Lipids and Lipoproteins and the Leucodystrophies (Neurochemistry Symposium. 7th Int. Congr. Neurol. Rome, 1961), edited by J. Folch-Pi and H. Bauer, pp. 169-186. Elsevier, Amsterdam.

- - (1966). Syndrome of micrencephaly, strio-cerebellar calcifications, and leucodystrophy. J. Neurol. Neurosurg. Psychiat., 29, 157-163.

- - Valentine, J. C., and Danby, T. A. (1962). Sudanophil leucodystrophy in a pachygyric brain. Ibid., 25, 363-369.

—, Urich, H., and Tingey, A. H. (1963). Leucodystrophy with predilection for cerebellum and brain stem. Acta neuropath. (Berl.), 2, 378-389.

Peiffer, J. (1962). Differentiation of various types of leukodystrophy. Wld Neurol., 3, 580-601.

krankheit. In Proc. 5th Int. Congr. Neuropath., Zurich, pp. 164-167.

_, and Zerbin-Rüdin, E. (1963). Zur Variationsbreite der PelizaeusMerzbacherschen Krankheit. Acta neuropath. (Berl), 3, 87-107.

Pelizaeus, F. (1885). Ueber eine eigenthümliche Form spastischer Lähmung mit Cerebralerscheinungen auf hereditärer Grundlage. (Multiple Sklerose.) Arch. Psychiat. Nervenkr., 16, 698710.

Poser, C. M. (1962). Concepts of dysmyelination. In Cerebral Sphingolipidoses, edited by S. M. Aronson and B. W. Volk, pp. 141164. Academic Press, New York.

Seitelberger, F. (1954). Die Pelizaeus-Merzbachersche Krankheit. Klinisch-anatomische Untersuchung zum Problem ihrer Stellung unter den diffusen Sklerosen. Wien. Z. Nervenheilk., 9, 228-289.

Spielmeyer, W. (1923). Der anatomische Befund bei einem zweiten Fall von Pelizaeus-Merzbacherscher Krankheit. Z Zbl. ges. Neurol. Psychiat., 32, 203.

Tingey, A. H., and Edgar, G. W. F. (1963). A contribution to the chemistry of the leucodystrophies. J. Neurochem., 10, 817-823.

Wicke, R. (1938). Ein Beitrag zur Frage der familiären diffusen Sklerosen einschliesslich der Pelizaeus-Merzbacherschen Krankheit und ihrer Beziehung zur amaurotischen Idiotie. Z. ges. Neurol. Psychiat. (orig.), 162, 741-766.

Zeman, W., Demyer, W., and Falls, H. F. (1964). Pelizaeus-Merzbacher disease: a study in nosology. J. Neuropath. exp. Neurol. 23, 334-354. 